Маркетинг в России и за рубежом. - 2015. - № 4. C. $47-54$.

4. Оберт T.Б. Анализ конкурентной среды и угроз конкуренции в российской экономике // Синтез науки и общества в решении глобальных проблем современности: сб. статей Междунар. науч.-практ. конф. (28 июля 2016 г., г. Уфа). - В 2 ч. - Ч.1. - Уфа: МЦИИ ОМЕГА САЙНС, 2016. - С. 89.

5. Суханова И.Ф., Лявина М.Ю. Импортозамещение как основа достижения продовольственной безопасности страны // Аграрный научный журнал. - 2015. - № 3. - С. 93-99.

6. Чан Ким В., Моборн Р. Стратегия «голубого океана». - М., 2013. - 216 c.
Коновалова Татьяна Леонидовна, старший преподаватель кафедры «Экономическая теория и национальная экономика», Саратовский национальный исследовательский государственный университет имени Н.Г. Чернышевского. Россия.

Оберт Татьяна Борисовна, старший преподаватель кафедры «Экономическая теория и национальная экономика», Саратовский национальный исследовательский государственный университет имени Н.Г. Чернышевского. Россия.

410013, г. Саратов, ул. Астраханская, 89.

Тел.: (8452) 21-36-44.

Ключевые слова: внутриотраслевая конкуренция; конкурентная стратегия; ценовая и неценовая конкуренция.

\title{
INTRA-BRANCH COMPETITION: STRATEGY AND METHODS
}

Konovalova Tatyana Leonidovna, Senior Teacher of the chair "Economic Theory and National Economics", Saratov National Research State University named after N.G. Chernyshevskiy. Russia.

Obert Tatyana Borisovna, Senior Teacher of the chair "Economic Theory and National Economics", Saratov National Research State University named after N.G. Chernyshevskiy. Russia.

Keywords: intra-branch competition; competitive strategy; price and not price competi-tion.
In the submitted article some aspects of the intra-branch competition, its' possible strategy and methods are investigated. The problems of stimulation of consumers measures of the price and not price competition applied in various branch markets are considered. As an example the situation of development of the competition in the Russian market of cheeses is shown. The condition of the Russian market of sugar as one of the highly competitive markets is analyzed.

удк 339.56

\section{ФАКТОРЫ ЭФФЕКТИВНОГО АГРОПРОДОВОЛЬСТВЕННОГО ИМПОРТОЗАМЕЩЕНИЯ В РОССИИ}

\author{
ЛЯВИНА Мария Юрьевна, Саратовский государственный аграрный университет \\ имени Н.И. Вавилова
}

Статья посвящена анализу факторов, определяющих достижение эффективного агропродовольственного импортозамещения в России. Проведена систематизация факторов по отдельным группам. Выделены внешние и внутренние факторы, влияющие на результаты проводимой аграрной политики. Представлены последствия воздействия отдельных факторов на функиионирование аграрной экономики. Раскрыты причины высокой импортозависимости агропродовольственного рынка. Осуществлена классификация внутренних факторов агропродовольственного импортозамещения по уровням воздействия. Предложены первоочередные мероприятия по нивелированию негативного влияния внешних и внутренних факторов на процесс продовольственного импортозамещения.

Введение. На развитие отечественного аграрного сектора оказывает влияние значительное количество макроэкономических процессов, происходящих как в рамках национальной экономики, так и на мировом рынке. Достижение параметров продовольственной безопасности как объявленной приоритетной задачи импортозамещения определяется совокупным влиянием множества разнонаправленных факторов, отличающихся степенью, временем и направленностью воздействия. Они предопределяют не только результаты производства отечественного сельского хозяйства, но и возможности перехода к экспортно ориентированному развитию различных отраслей аграрной экономики. В свою очередь, достигнутые показатели темпов роста и развития предопределяют необходимость корректировки проводимой аграрной политики. Совокупное воздействие внешних и внутренних факторов может способствовать или затруднять решение задач импортозамещения продовольствия.

Особую важность на современном этапе достижения продовольственной безопасности и импортозамещения приобреливнешние факторы как внешнеэкономические, так и внешнеполитические. Нестабильная геополитическая ситуация заставила правительство использовать административные способы регулирования внешнеэкономической деятельности, а именно - введение ответных мер на санкции западных стран. В свою очередь, введение продовольственного эмбарго стало основной причиной формирования нового подхода к долгосрочной стратегии развития отечественного аграрного сектора. Необходимость 
обеспечения продовольственной безопасности и снижения зависимости от импорта наиболее значимой продукции предопределила переход к политике ускоренного импортозамещения продовольствия.

методика исследований. Исследование основывается на принципах классической экономической теории, теории импортозамещения, теории сравнительных преимуществ международной торговли. Теоретические и методологические основы исследования включают как работы российских ученых $[1,2,3,8,9]$, так и нормативно-правовые документы.

Предлагаемые методы исследования: экономико-статистические, используемые для оценки динамики процесса импортозамещения; расчетно-конструктивный метод; метод сравнительного анализа и экспертных оценок. Помимо специфических методов использованы всеобщие и общенаучные подходы: диалектика, абстрагирование, дедукция, индукция, анализ и синтез.

Результаты исследований. Эффективность реализуемой политики импортозамещения продовольствия складывается под воздействием совокупности факторов, влияющих на состояние национальной аграрной экономики. Синергетический эффект от их совместного воздействия проявляется в отклонении от намеченных целевых показателей продовольственной безопасности.

Внешние факторы, определившие введение политики импортозамещения продовольствия, формируются на мировых рынках в глобальном экономическом пространстве. Большая их часть является следствием естественного процесса экономического развития - формирования глобальной инновационной экономики, нарастания интеграционных процессов, демографического роста. Также внешние факторы могут стать следствием административных решений, как, например, введение санкций. Они, в свою очередь, нарушают условия международной торговли, замедляют темпы экономического роста, препятствуют свободному передвижению капиталов.

Внешними факторами естественного (эволюционного) происхождения, оказывающими влияние на импортозамещение продовольствия в России, являются:

усиление процессов глобализации, углубление международного разделения труда. Глобализация мирохозяйственных связей делает режим развития агропродовольственного комплекса страны всё более либеральным. Учитывая угрозы и риски, которые связаны с интеграцией российского продовольственного комплекса в мировую агроэкономику, необходимо максимально использовать возможности и стимулы развития внешнеэкономических связей. Несмотря на неоднозначное воздействие глобализации на экономику страны, данные процессы могут дать дополнительные импульсы и шансы для его выхода на траекторию устойчивого развития [8]. Искусственное ограничение внешнеэкономической деятельности приводит к потере потенциальных доходов. Отказ от участия в мирохозяйственных связях, даже отдельными секторами, наносит существенный ущерб экономике страны в целом. Ориентация на импортозамещение в аграрном секторе предполагает не искусственное ограничение импорта для замены его отечественными аналогами, а развитие конкурентоспособных производств, способных обеспечить потребности не только внутри страны, но и войти в глобальную продовольственную систему. В этой связи отечественный агропродовольственный сектор должен не только решить накопившиеся проблемы, но и выйти на новый уровень развития;

углубление процессов интеграции. Развитие ЕАЭС является важным фактором, определяющим результаты стратегии импортозамещения продовольствия, направленной на развитие экспортно ориентированных производств. В настоящее время ЕАЭС формирует рынок с более чем 183 млн потребителей, унифицированным законодательством, свободным передвижением капиталов, услуг и рабочей силы. Эскалация экономических санкций предопределяет необходимость отечественных сельскохозяйственных производителей ориентироваться на рынки новых стран. Развитие дальнейшего экономического сотрудничества с зарубежными странами связано, в первую очередь, с переориентацией внешнеэкономических связей в сторону стран ближнего зарубежья, а именно - ЕАЭС, вхождение на рынки которых не ограничено дополнительными административными и таможенными барьерами;

усиление геополитической напряженности. Введение в отношении России экономических санкций, которые были поддержаны 48 странами, предопределило вектор дальнейшего развития экономики. Приоритетом государственной аграрной политики стало импортозамещение, необходимое для обеспечения продовольственной независимости страны. Под эмбарго попала примерно пятая часть импорта продовольствия как симметричный ответ на санкции [1]. Очевидной стала необходимость обеспечения населения важнейшими видами продовольствия собственного производства, увеличения государственной поддержки сельского хозяйства, совершенствования государственной аграрной политики, смены приоритетов в развитии отечественной экономики. Введение санкций, с одной сторо- 
ны, предопределило необходимость совершенствования государственной аграрной политики, перехода к опережающему импортозамещению и поиска новых стратегических подходов к формированию продовольственной независимости России. С другой стороны, продуктовое эмбарго вызвало появление новых проблем в обеспечении населения отечественным продовольствием, а именно - сокращение возможностей внешнего финансирования инвестиционных проектов, необходимость увеличения государственной поддержки сельскохозяйственных производителей на фоне дефицита бюджета, значительный отток капитала, снижение интереса иностранных инвесторов;

изменение конъюнктуры мировых сырьевых рынков. Темпы роста и развития отечественной экономики находятся в прямой зависимости от экспорта углеводородов. Динамика нефтяных котировок является важнейшим фактором, определяющим наполняемость российского бюджета, курс национальной валюты, макроэкономическую ситуацию в стране в целом. Необходимость сокращения бюджетных расходов приводит к пересмотру возможностей государственной поддержки отдельных отраслей экономики. Сложившийся бюджетный дефицит предопределяет сокращенное субсидирование отечественного агропродовольственного сектора, а, значит, и динамику процесса импортозамещения. Вместе с тем диверсификация отечественной экономики, переход к экспортно ориентированному производству позволят снизить сложившуюся зависимость;

естественное повышение конкуренции на мировом продовольственном рынке. Активное развитие генной инженерии, технологий точно- го земледелия, интенсивное ведение сельскохозяйственного производства в западных странах привело не только к значительному росту внутреннего производства и переходу к новому технологическому укладу, но и вынудило проводить агрессивную экспортную политику, осваивать быстро растущие рынки сбыта развивающихся стран, активно включаться в международные технологические цепочки. Отечественные предприятия пока не могут предложить мировому рынку конкурентоспособную продукцию. Важнейшей причиной является более низкая производительность труда в сравнении с зарубежными странами (см. таблицу).

Достигнутый уровень производительности труда не позволяет на равных конкурировать на мировом продовольственном рынке, в полной мере обеспечивать возрастающие потребности населения в качественном продовольствии, наращивать экспортные поставки продукции с высокой добавленной стоимостью. Позиции России в качестве одного из мировых лидеров по производству пшеницы, маслосемян подсолнечника, сахарной свеклы связаны с использованием природного потенциала страны, а не с высокотехнологичным развитием отрасли сельскохозяйственного производства.

Внутренние факторы также играют немаловажную роль в обеспечении импортозамещения. От них в значительной степени зависят не только конечные результаты производства, но и зачастую сама возможность его ведения. Если большинство внешних факторов отражают естественный путь развития мировой экономики, то внутренние факторы являются следствием реализуемой в стране социально-экономической и аграрной политики. Все факторы, оказывающие

Сравнение показателей производительности труда в сельском хозяйстве России и зарубежных стран, 2014 г. [5, 7, 10]

\begin{tabular}{|c|c|c|c|c|c|c|c|c|}
\hline Показатель & 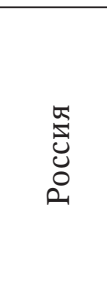 & 莺 & 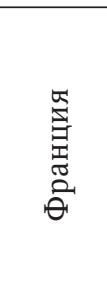 & 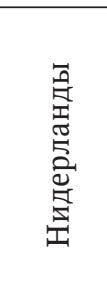 & 罗 & 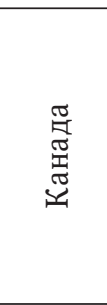 & |心 & 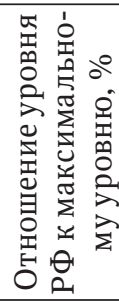 \\
\hline $\begin{array}{l}\text { Урожайность, ц/га, в том числе: } \\
\text { зерновые и зернобобовые }\end{array}$ & 24,1 & 79,9 & 57,8 & 89,9 & 75,2 & 33,9 & 57,6 & 26,8 \\
\hline кукуруза & 43,6 & 106,8 & 100,0 & 137,4 & 107,3 & 93,6 & 60,0 & 31,7 \\
\hline подсолнечник & 13,1 & 23,0 & 23,7 & - & 16,5 & 18,9 & 25,6 & 51,2 \\
\hline картофель & 150 & 474 & 479 & 457 & 472 & 330 & 170 & 31,3 \\
\hline овощи & 191,8 & 313,1 & 250,8 & 276,5 & 713,4 & 290,4 & 162,3 & 26,9 \\
\hline сахарная свекла & 370 & 799 & 924 & - & 613 & 717 & 490 & 40,0 \\
\hline Надой на 1 корову, кг & 4029 & 7541 & 6850 & 7747 & 10150 & 8811 & 2994 & 39,7 \\
\hline $\begin{array}{l}\text { Валовая добавленная стоимость сель- } \\
\text { ского хозяйства на } 1 \text { работника, долл. } \\
\text { (в ценах } 2010 \text { г.) }\end{array}$ & 10893 & 32521 & 94946 & 76633 & 76456 & 83938 & 1398 & 11,5 \\
\hline
\end{tabular}


влияние на развитие сельского хозяйства и, как следствие, наполняемость внутреннего продовольственного рынка, можно разделить на несколько групп по уровням и возможности регулирования.

Факторы, действующие на макроуровне, в целом определяют развитие аграрного производства в стране. К ним отнесятся следующие:

макроэкономическая стабильность. Стабильная экономическая ситуация позволяет более точно спрогнозировать развитие отраслей экономики, осуществлять реализацию государственных программ в области сельского хозяйства в запланированных объемах, расширять государственную поддержку отрасли. Низкий уровень инфляции, стабильная ситуация на валютном рынке приводят к смягчению денежнокредитной политики Центрального банка, в частности, к снижению ключевой ставки. Последнее, в свою очередь, увеличивает возможности товаропроизводителей в сфере кредитования;

валютный курс, определяющий привлекательность российского рынка для иностранных поставщиков и возможность отечественных экспортеров выхода на внешние рынки. Российский рубль в значительной степени подвержен колебаниям вследствие сохраняющейся зависимости от нефтяных котировок. Снижение цен на «черное золото» неизменно приводит к обесцениванию национальной валюты, росту инфляции, сокращению платежеспособности населения, замедлению темпов экономического роста. От значительного снижения курса рубля, произошедшего в 2014-2015 гг. должны были выигрывать экспортеры, которые реализуют продукцию на внешних рынках и одновременно ведут бизнес внутри страны. Но, как известно, в области сельского хозяйства таковых единицы. Вследствие высокой зависимости от импорта, дополнительные доходы экспортеров, полученные от реализации продукции за рубеж по более низким ценам в пересчете на доллары, нивелируются ростом стоимости ввозимого сырья и материалов. В данной связи валютный курс не является оптимальным инструментом осуществления импортозамещения, поскольку не позволяет сформировать дополнительные доходы для инвестирования и ведения расширенного воспроизводства;

усиливающийся диспаритет цен на промышленную и сельскохозяйственную продукцию. Одной из причин низкой производительности труда в аграрном секторе является постоянное удорожание промышленной продукции и неэквивалентность обмена. Так, если в 2010 г. для приобретения трактора универсального необходимо было реализовать 363 т пшеницы, то в 2016 г. - уже 465 т;

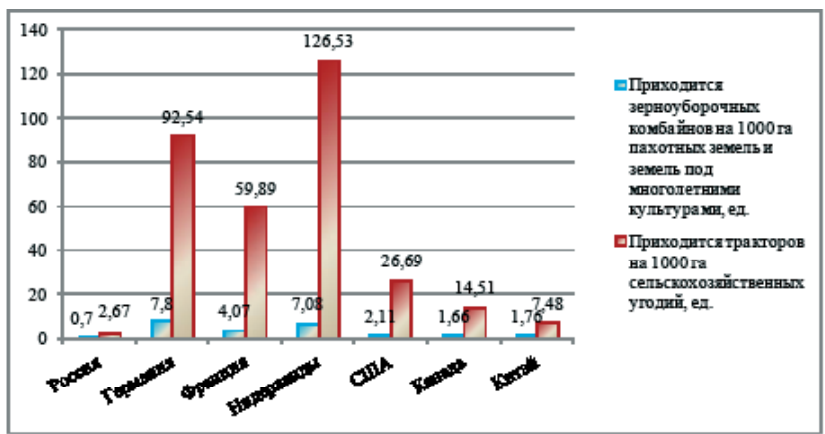

Рис. 1. Показатели обеспеченности сельскохозяйственной техникой России и западных стран [2]

отсталая материально-техническая база сельского хозяйства. Последствиями неэквивалентного обмена продукции сельского хозяйства на необходимые средства производства стали физический и моральный износ техники, сокращение обеспеченности предприятий современной техникой, снижение производительности труда, замедление темпов обновления машинно-тракторного парка. В настоящее время сельскохозяйственная техника в России не отвечает поставленным задачам по количественному и качественному составу, а также не соответствует современному, высокоинтенсивному развитию аграрной сферы западных стран (рис. 1).

В последние годы темпы обновления тракторов составляют всего 3 \%, а зерноуборочных комбайнов - менее 5 \% [1]. С учетом современного уровня технического обеспечения формирование аграрного сектора, способного не только обеспечивать внутренние потребности, но и конкурировать с лидерами мировой агропродовольственной системы, является весьма сложной задачей. По сути, «в стране при наличии значительных производственных ресурсов не созданы условия для формирования ее конкурентного потенциала» [2, с. 56]. Таким образом, рассматриваемый фактор становится определяющим для увеличения темпов роста аграрного производства, решения задач ускоренного импортозамещения и обеспечения продовольственной независимости страны;

доступность кредитов. Решение проблем импортозамещения связано в первую очередь с возможностью ведения производства на современной материально-технической базе с одновременным внедрением научно-технических достижений, что позволит не только обеспечить внутренние потребности, но и выйти на зарубежные рынки не в качестве экспортеров сырьевых товаров, а готовой продовольственной продукции. Развитие производства, внедрение инноваций, реализация инвестиционных проектов осуществляется с привлечением кредитных ресурсов. Однако в настоящее время большинству сельскохозяйственных товаропроизводителей 
недоступны кредитные ресурсы по причине достаточно высокой стоимости кредитных ресурсов, необходимых для проведения сезонных работ и материально-технического обновления;

государственное регулирование сельскохозяйственного производства. Обеспечение агропродовольственного импортозамещения возможно лишь при изменении самого концепта аграрной политики, ориентированной на всестороннюю поддержку внутреннего производства продовольствия, повышение его доходности и увеличение экспортных поставок на основе различных мер государственного регулирования. Импортозамещение необходимо рассматривать только «в увязке с экспортной политикой государства» [9, с. 5]. Сложившийся организационно-экономический механизм функционирования аграрного сектора не способствует развитию конкурентоспособного производства, выходу его на новый технологический уровень, ориентации на внешние продовольственные рынки;

развитость финансового рынка, а именно наиболее важных для сельского хозяйства секторов - инвестиционного, кредитного, страхового. В рамках Государственной программой развития сельского хозяйства и регулирования рынков сельскохозяйственной продукции, сырья и продовольствия на 2013-2020 годы реализуется подпрограмма «Развитие финансово-кредитной системы агропромышленного комплекса», объем финансирования которой в 2015-2016 гг. составил 20 млрд руб. [4]. Она направлена на обеспечение стабильного привлечения инвестиций в АПК, в том числе для поддержки и активизации процесса продовольственного импортозамещения.

Наращивание объемов внутреннего производства, выполнение задач импортозамещающей политики и дальнейший выход на зарубежные продовольственные рынки требует значительных инвестиций. Для стимулирования инвестиционной деятельности в АПК и повышения доступности заемных средств для сельскохозяйственных товаропроизводителей в рамках Госпрограммы предусмотрены такие меры государственной поддержки, как возмещение части

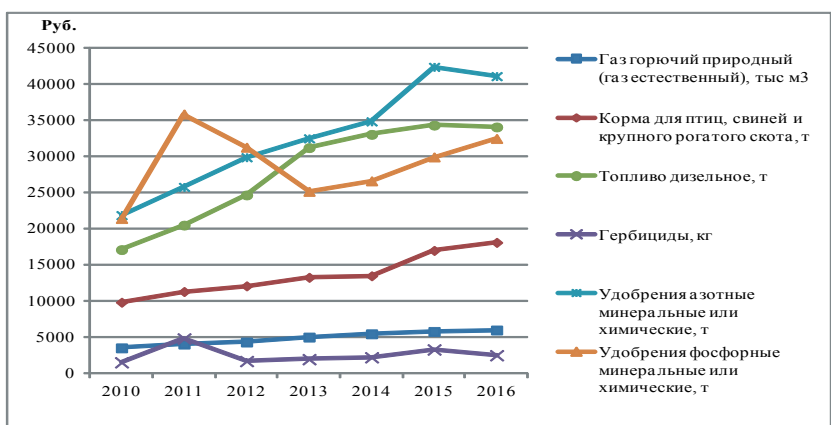

Рис. 2. Динамика цен на отдельные виды ресурсов для сельского хозяйства по годам [5] процентной ставки по привлеченным краткосрочным и инвестиционным кредитам и займам;

рост тарифов для сельского хозяйства и цен на основные виды ресурсов. Начиная с 2010 г. произошел почти двукратный рост цен на ресурсы для сельского хозяйства (рис. 2).

В конечном итоге рост тарифов и цен на ресурсы в значительной степени ограничивает рост внутреннего производства и его инновационное развитие, высокой остается импортоемкость отечественной продукции, а проблема импортозамещения решается не в полной мере.

К внутренним факторам второй группь, оказывающим влияние на процесс импортозамещения, можно отнести те, которые определяют развитие производства на мезоуровне:

неблагоприятные природно-климатические условия возделывания. Большинство российских регионов сталкиваются с непредсказуемостью погодных условий, определяющих результативность деятельности. При этом большинство сельскохозяйственных организаций не в состоянии воспользоваться инструментом страхования деятельности по причине нехватки денежных средств, что приводит к ухудшению финансового положения и банкротству. В данном случае необходимо осуществлять повышение степени интенсивности сельскохозяйственного производства, что позволит минимизировать потери от природных катаклизмов. В настоящее время площади используемых в сельском хозяйстве мелиорируемых земель составляют всего 6,1 \% от площади пашни, доля посевов элитных семян в площади пашни - 8 \%, объем внесения удобрений сельскохозяйственными организациями - 48,31 кг/га [5]. Для сравнения - внесение удобрений в расчете на 1 га в Германии составляет 203,5 кг, Франции 140,6 кг, Нидерландах - 231,1 кг, США - 131,9 кг, Китае - 364,4 кг [2];

неудовлетворительное состояние дорожнотранспортной и логистической инфраструктуры. Отсутствие необходимого количества современных оптово-логистических центров, терминалов, высокие тарифы на перевозку грузов, проблемы с дорожным покрытием препятствуют достижению целевых показателей импортозамещения, поскольку затрудняет реализацию произведенной продукции, снижает товарность и эффективность производства. Проблема сбыта усложняется тем, что многие виды продукции являются скоропортящимися, требующими особых условий хранения. Однако отсутствие коммуникаций, необходимых для сбыта продукции, не позволяет увеличивать объемы межрегиональных и экспортных поставок. Развитие инфраструктуры агропродовольственного рынка является важ- 
нейшим условием дальнейшего развития АПК, поскольку она позволяет минимизировать потери продукции на местах и обеспечивает условия для гарантированного сбыта произведенной продукции;

отсутствие достаточного количества селекционно-генетических и научных центров, способных обеспечить товаропроизводителей необходимыми ресурсами. Высокая зависимость сельского хозяйства от поставок ресурсов и технологий делают решение задачи агропродовольственного импортозамещения весьма сложным и дорогим. Даже незначительное ослабление курса национальной валюты приведет к росту цен на продовольствие.

Использование иностранных технологий и даже их отдельных элементов приводит к тому, что при возделывании сельскохозяйственных культур возникает необходимость приобретения всех элементов данной технологии в комплексе для получения максимального эффекта. Таким образом, отечественные предприятия финансируют зарубежныеэкономики, а российские разработки, адаптированные к имеющимся условиям, становятся невостребованными. Рост импорта материальных ресурсов на фоне недостаточного развития собственного производства ведет к увеличению степени импортоемкости продукции. Сложившаяся ситуация создает скрытую угрозу национальной продовольственной независимости, которая намного «опаснее избыточного присутствия на отечественном рынке импортного продовольствия» [3, с. 44];

обеспеченность трудовыми ресурсами. Важнейшим фактором, определяющимпроизводительность труда, эффективность организации и управления производством, достижения целевых показателей агропродовольственного импортозамещения является наличие трудовых ресурсов определенной квалификации. Снижение привлекательности сельского труда, неразвитость социальной инфраструктуры, низкий уровень заработной платы препятствуют росту конкурентоспособной продукции. Так, размер среднемесячной номинальной начисленной заработной платы в сельском хозяйстве в 2016 г. составил 59,3 \% от средней по экономике [5]. В данном случае речь идет не только об экономическом, но и о социальном аспекте политике импортозамещения, которое обеспечивает рост занятости населения, улучшение продовольственного обеспечения, рост благосостояния, увеличение потребности в высококвалифицированных кадрах, замедление миграционных процессов.

К факторам третьей группь можно отнести факторы микроуровня, определяющие характер процесса импортозамещения на уровне предприятий: сознательное упрощение технологического процесса. Неудовлетворительное финансовое состояние вынуждает многих сельскохозяйственных товаропроизводителей исключать отдельные операции или сводить их к минимуму, например, частично использовать средства защиты растений и удобрения;

выборочное использование элементов иностранных технологий в производственном цикле. Многие организации приобретают импортные семена, отдельные сельскохозяйственные машины, премиксы и иные ресурсы. Однако большинство из них не имеют возможности приобрести полный «шлейф». Как результат - более низкие показатели продуктивности и урожайности в сравнении с западными странами;

внедрение отечественных НИОКР в производство. Высокая зависимость от импортных технологий, низкий процент внедрения отечественных новшеств в производство, неутешительное состояние многих научно-исследовательских учреждений предопределяют высокую импортозависимость. Для решения проблем продовольственного обеспечения и экпортного ориентирования АПК необходима активизация научной деятельности, повышение заинтересованности отечественных предприятий в отечественных разработках, усиление связи между наукой и производством. По данным Росстата, за 2014-2016 гг. доля сельского хозяйства, охоты и лесного хозяйства в общей сумме внутренних затрат на научные исследования и разработки не превышала 0,06 \%, или 583,8 млн руб. [5]. Нельзя не согласиться, что без заказов со стороны сельского хозяйства «наука обречена на деградацию даже в относительно благоприятных финансовых условиях» [6, с. 420];

отказ от организационных и маркетинговых инноваций. Внедрение маркетингового подхода к управлению позволяет предприятиям быстрее адаптироваться к изменениям внешних условий, ориентироваться на требования потребителей, поставлять на рынок востребованную продукцию. Стоит отметить, что инновационная активность сельскохозяйственных организаций в данной сфере достаточно низкая. В 2016 г. доля сельскохозяйственных организаций, осуществлявших технологические, организационные, маркетинговые инновации в растениеводстве, составил всего $4,2 \%$, животноводстве $-4,7 \%$ [5].

В целом соотношение внешних и внутренних факторов определяет динамику развития сельского хозяйства в целом, а также возможности и результаты процесса импортозамещения. Представленные факторы являются динамичными, оказывают разнонаправленное воздействие и различаются по степени и срокам нивелирова- 
ния влияния в зависимости от складывающихся экономических условий. Изменение соотношения степени их воздействия определяет сроки достижения целевых ориентиров проводимой аграрной политики.

Заключение. Основываясь на вышеизложенном, можно прийти к выводу, что агропродовольственное импортозамещение является объективно необходимым для обеспечения продовольственной безопасности, сокращения зависимости от внешних поставок и стабилизации внутренней макроэкономической ситуации. В настоящее время особую роль играют внешние факторы, отражающие состояние мирового рынка и его конъюнктуру. Для нивелирования воздействия данной группы факторов необходимо развитие внутреннего производства, широкомасштабные инвестиции в агропродовольственную систему, обновление материально-технической базы, повышение производительности труда.

Предложенная систематизация внутренних факторов позволяет определить стратегические ориентиры и конкретные мероприятия, позволяющие скорректировать существующую аграрную политику с целью достижения агропродовольственного импортозамещения. Необходима новая парадигма аграрного производства, позволяющая не только решить внутренние продовольственные проблемы, но и перейти к экспортному ориентированию экономики. Рост насыщения внутреннего рынка, снижение импортной емкости продовольственной продукции, развитие внешнеторговой деятельности связаны в первую очередь с решением накопившихся системных проблем в аграрном секторе. Развитие финансового рынка, ускорение научно-технического прогресса, внедрение отечественных инноваций, диверсификация производства, переход на мировые стандарты качества пищевой и сельскохозяйственной продукции позволят не только решить проблему ускоренного импортозамещения, но и обеспечить улучшение макроэкономической ситуации.

\section{СПИСОК ЛИТЕРАТУРЫ}

1. Алтухов А.И. Импортозамещение в агропродовольственном комплексе страны: проблемы и пути их решения // Вестник Курской государственной сельскохозяйственной академии. - 2015.- № 3. - С. 2-6.

2. Анохина M.Е., Середина Н.С. Конкурентоспособность отечественного АПК: проблемы, решения // Экономика и управление народным хозяйством. - 2016. № 1(134). - С. 51-57.

3. Голубев А.В. Развитие АПК на основе отечественных инноваций как условие импортозамещения // Экономика сельскохозяйственных и перерабатывающих предприятий. - 2015. - № 2. - С. 42-47.

4. Национальный доклад «О ходе и результатах реализации в 2016 году Государственной программы развития сельского хозяйства и регулирования рынков сельскохозяйственной продукции, сырья и продовольствия на 2013-2020 годы». - Режим доступа: http://mcx.ru/upload/iblock/e1c/e1ca23b6bd685c961 ed636284f6f18fe.pdf.

5. Официальный сайт Федеральной службы государственной статистики. - Режим доступа: http:// www.gks.ru/.

6. Продовольственная безопасность России и стратегия импортозамещения в условиях глобальных вызовов / А.А. Анфиногентова [и др.]; под общ. ред. И.Л. Воротникова. - Саратов: Саратовский источник, 2015. - 444 c.

7. Продовольственная и сельскохозяйственная организация Объединенных Наций. - Режим доступа: http://www.fao.org/faostat/ru/\#data.

8. Суханова И.Ф., Лявина М.Ю., Перебинос А.В. Россия на мировом рынке продовольствия: реалии и перспективы // Аграрный научный журнал. - 2012. № 8. - С. 88-94.

9. Ушачев И.Г. Научные проблемы импортозамещения и формирования экспортного потенциала продукции агропромышленного комплекса России // АПК: Экономика, управление. - 2016. - № 1. - С. 4-22.

10. The World Bank. - URL: https://data.worldbank. org/indicator/EA.PRD.AGRI.KD.

Лявина Мария Юрьевна, канд. экон. наук, доцент кафедры «Маркетинг и внешнеэкономическая деятельность», Саратовский государственный аграрный университет имени Н.И. Вавилова. Россия.

410012, г. Саратов, Театральная пл., 1.

Тел.: (8452) 23-72-60.

Ключевые слова: импортозамещение; продовольствие; эмбарго; продовольственная безопасность; фактор.

\section{FACTORS OF EFFECTIVE AGRICULTURAL IMPORT SUBSTITUTION IN RUSSIA}

Lyavina Mariya Yuryevna, Candidate of Economic Sciences, Associate Professor of the chair "Marketing and Foreign Economic Activity”, Saratov State Agrarian University named after N.I. Vavilov, Russia. factor.

Keywords: import substitution; food; embargo; food security;

The article is devoted to analysis of the factors determining the achievement of effec-tive food import substi- tution in Russia. Classification of the factors for certain groups is generated. External and internal factors affecting the outcome of ongoing agricultural pol-icy are selected. Effects of individual factors on the functioning of the agrarian economy are presented. The reasons for the high dependence on imports in the food market are revealed. Classification of internal factors agro-food import substitution on exposure is conducted. Priority actions for leveling the negative impact of external and internal factors on the proc-ess of food import substitution are proposed. 